\title{
APPROXIMATING FIXED POINTS OF THE COMPOSITION OF TWO RESOLVENT OPERATORS
}

\author{
OGANEDITSE A. BOIKANYO \\ Department of Mathematics and Statistical Sciences Botswana \\ International University of Science and Technology Private Bag 16, Palapye, Botswana \\ E-mail: boikanyoa@gmail.com
}

\begin{abstract}
Let $A$ and $B$ be maximal monotone operators defined on a real Hilbert space $H$, and let $\operatorname{Fix}\left(J_{\mu}^{A} J_{\mu}^{B}\right) \neq \emptyset$, where $J_{\mu}^{A} y:=(I+\mu A)^{-1} y$ and $\mu$ is a given positive number. [H. H. Bauschke, P. L. Combettes and S. Reich, The asymptotic behavior of the composition of two resolvents, Nonlinear Anal. 60 (2005), no. 2, 283-301] proved that any sequence $\left(x_{n}\right)$ generated by the iterative method $x_{n+1}=J_{\mu}^{A} y_{n}$, with $y_{n}=J_{\mu}^{B} x_{n}$ converges weakly to some point in $\operatorname{Fix}\left(J_{\mu}^{A} J_{\mu}^{B}\right)$. In this paper, we show that the modified method of alternating resolvents introduced in [O. A. Boikanyo, A proximal point method involving two resolvent operators, Abstr. Appl. Anal. 2012, Article ID 892980, (2012)] produces sequences that converge strongly to some points in $\operatorname{Fix}\left(J_{\mu}^{A} J_{\mu}^{B}\right)$ and $\operatorname{Fix}\left(J_{\mu}^{B} J_{\mu}^{A}\right)$.

Key Words and Phrases: Maximal monotone operator, alternating resolvents, proximal point algorithm, nonexpansive map, resolvent operator.
\end{abstract}

2010 Mathematics Subject Classification: 47J25, 47H05, 47H09, 47H10.

Acknowledgment. The author would like to sincerely thank Professor Simeon Reich for his valuable comments that improved the presentation of this manuscript.

\section{REFERENCES}

[1] H.H. Bauschke, P.L. Combettes, S. Reich, The asymptotic behavior of the composition of two resolvents, Nonlinear Anal., 60(2005), no. 2, 283-301.

[2] H.H. Bauschke, E. Matoušková, S. Reich, Projection and proximal point methods: convergence results and counterexamples, Nonlinear Anal., 56(2004), no. 5, 715-738.

[3] O.A. Boikanyo, A proximal point method involving two resolvent operators, Abstr. Appl. Anal. 2012, Article ID 892980, 2012, 12 p.

[4] O.A. Boikanyo, G. Moroşanu, Inexact Halpern-type proximal point algorithm, J. Glob. Optim., 51(2011), no. 1, 11-26.

[5] O.A. Boikanyo, G. Moroşanu, A contraction proximal point algorithm with two monotone operators, Nonlinear Anal., 75(2012), no. 14, 5686-5692.

[6] O.A. Boikanyo, G. Moroşanu, On the method of alternating resolvents, Nonlinear Anal., $\mathbf{7 4}(2011), 5147-5160$

[7] O.A. Boikanyo, G. Moroşanu, Strong convergence of the method of alternating resolvents, J. Nonlinear Convex Anal., 14(2013), no. 2, 221-229.

[8] L.M. Bregman, The method of successive projection for finding a common point of convex sets, Sov. Math. Dokl., 6(1965), 688-692.

[9] L. Hu, L. Liwei, A new iterative algorithm for common solutions of a finite family of accretive operators, Nonlinear Anal., 70(2009), 2344-2351. 
[10] H. Hundal, An alternating projection that does not converge in norm, Nonlinear Anal., 57(2004), no. $1,35-61$.

[11] S. Kamimura, W. Takahashi, Approximating solutions of maximal monotone operators in Hilbert spaces, J. Approx. Theory, 106(2000), 226-240.

[12] E. Kopecká, S. Reich, A note on the von Neumann alternating projections algorithm, J. Nonlinear Convex Anal., 5(2004), 379-386.

[13] E. Matoušková, S. Reich, The Hundal example revisited, J. Nonlinear Convex Anal., 4(2003), 411-427.

[14] N. Lehdili, A. Moudafi, Combining the proximal algorithm and Tikhonov regularization, Optimization, 37(1996), 239-252.

[15] G. López, V. Martín-Márquez, F. Wang, H.K. Xu, Forward-Backward Splitting Methods for Accretive Operators in Banach Spaces, Abstr. Appl. Anal. 2012, Article ID 109236, 2012, 25 p.

[16] P.E. Maingé, Strong convergence of projected subgradient methods for nonsmooth and nonstrictly convex minimization, Set-Valued Anal., 16(2008), 899-912.

[17] G. Moroşanu, Nonlinear Evolution Equations and Applications, Reidel, Dordrecht, 1988

[18] O. Nevanlinna, S. Reich, Strong convergence of contraction semigroups and of iterative methods for accretive operators in Banach spaces, Israel J. Math., 32(1979), 44-58.

[19] F. Wang, H. Cui, On the contraction-proximal point algorithms with multi-parameters, J. Glob. Optim., 54(2012), 485-491.

[20] H.K. Xu, Iterative algorithms for nonlinear operators, J. London Math. Soc., 66(2002), no. 2, 240-256.

[21] H.K. Xu, A regularization method for the proximal point algorithm, J. Glob. Optim., 36(2006), $115-125$.

[22] H. Zegeye, N. Shahzad, Strong convergence theorems for a common zero of a finite family of m-accretive mappings, Nonlinear Anal., 66(2007), 1161-1169.

[23] H. Zegeye, N. Shahzad, Proximal point algorithms for finding a zero of a finite sum of monotone mappings in Banach spaces, Abstr. Appl. Anal. 2013, Article ID 232170, 2013, 7 p.

Received: April 25, 2014; Accepted: October 23, 2014. 
